(RESEARCH ARTICLE)

\title{
Designing a semantic intelligence-based planning framework in the ministry of science, research and technology with two macro and detailed approaches
}

\author{
Ahad Banar ${ }^{1}$, Azizollah Memariani ${ }^{2, *}$, Ali Rezaeian ${ }^{3}$ and Ali Moeini 4 \\ 1 Ph.D, Department of Public Management, Central Tehran Branch, Islamic Azad University, Tehran, Iran. \\ 2 Professor, Faculty of Computer and Electrical Engineering, Kharazmi University, Tehran, Iran. \\ 3 Professor, Faculty of Management and Accounting, Shahid Beheshti University, Tehran, Iran. \\ ${ }^{4}$ Professor, Faculty of Engineering Sciences, University of Tehran, Tehran, Iran.
}

Publication history: Received on 01 September 2020; revised on 06 September 2020; accepted on 09 September 2020

Article DOI: https://doi.org/10.30574/wjarr.2020.7.3.0332

\begin{abstract}
Semantic data management in organizations requires careful design of the appropriate semantic planning model that can best drive the organization to its goals. Therefore, designing a semantic framework to make decisions with minimum error and intelligent use of semantic data is inevitable. Lack of a smart or systematic model or lack of a system in place, lack of timely and appropriate decision making, lack of evidence-based planning processes, departures from governance tasks and addressing or drowning in operational and ongoing work. There are reasons why organizations, especially the Ministry of Science, Research and Technology, need to design an appropriate model for this purpose. The purpose of the present study is to design an appropriate and effective planning model in the Ministry of Science, Research and Technology in a macro and detailed manner. For this purpose, in the first phase of the research, macro-planning Framework was developed in the Ministry of Science, Research and Technology by designing a heuristic research approach using qualitative research method with Grounded theory. Then, in the second phase, a detailed planning Framework at the Ministry of Science, Research and Technology was designed using the Structured Analysis Method (SSADM). The quality of the designed pattern in both phases of research was evaluated and validated using scientific methods. Finally, the designed model was analyzed and explained and suggestions for future research were presented.
\end{abstract}

Keywords: Semantic data; Business intelligence; Pattern design; Intelligent organization.

\section{Introduction}

The socio-economic aspect of the organization has required it to look for tools to facilitate the business process, using data effectively, process and analyze them extensively from a variety of sources to build the foundation for the discovery of new knowledge. Nowadays organizations are more focused on collecting, creating and storing data from a variety of sources than before. Managing this massive amount of data and converting them into the useful information in the time of decisions has posed a great challenge.

Small, medium and large organizations require rapid access to semantic data that obtained from different organizational systems [1]. Management information systems have supported and assisted organizations in their various tasks for many years. However, they have not been able to integrate the scattered and heterogeneous data across different datasets to interpret the existing dependencies among the new data effectively. Also with the emergence of new topics in today's world, especially information technology, a new look has emerged in the design of patterns and systems. The importance of moving to the intelligent patterns and required for the organizations for using automated machines in the purpose of reducing possible failures can motivate the organizations to implement intelligent planning patterns.

\footnotetext{
* Corresponding author: Azizollah Memariani

Professor, Faculty of Computer and Electrical Engineering, Kharazmi University, Tehran, Iran.
} 
Therefore, recognition of these systems especially in management aspects is very necessary and should be studied in the form of models and systems of organizational planning in order to support and make smart the decision-making process. Intelligence refers to the process of converting raw data into business, operational and management information that assist decision makers to make their decisions better and faster and to act on the right information [2]. Organizational intelligent can be regarded as the effective, proper and fast use of the data, information, knowledge, and wisdom of individuals inside and outside the organization in deciding at different levels of the organization. Making decisions based on accurate, correct, on time and adequate information and semantic data depends on an understanding of the internal and external issues of the organization and the importance of making the right decisions for managers. In order for organizations to be able to respond quickly to market changes, they need systems that can represent different cause and effect analysis. Intelligent systems do not provide decision-makers with raw information. They rather analyze it and provide managers with intelligent decision packages or analytical reports. In order to make decisions with the least failure organizations need to have an understanding of a powerful tool for identifying an optimal decision-making process which is intelligent using data and information. One of the most important tools in this field is business intelligence (BI) that visually depicts targeted information. In fact, business intelligence is an important tool for designing Appropriate and intelligent decision-making models and systems in organizations.

This tool makes it possible for organizations to use organizational data at the right time and way to have an intelligent decision making process.

The data is processed by logging into business intelligence and converted into knowledge. Then the gained knowledge is analyzed and with its analytical result, managers can use these results in the decision making process and improve the performance of the organization. Accordingly, the result is clear that in designing patterns and decision-making systems such as the Planning pattern, the proper flow of data and information, their processing and conversion into knowledge, must be considered as an important matter. And Based on that should take steps into designing intelligent decision making patterns. Organizations will be able to intelligent the decision-making process with proper and timely using data. Larger organizations considering the huge amount of data are able to use this method in order to design more efficient decision-making patterns. Due to the huge amount of external and internal data affecting its performance, the Ministry of Science, Research and Technology needs an appropriate, intelligent and effective model so that the decision-makers can follow the best planning path. These ministries like other organizations need to make proper use of Information and Communications Technology tools, especially using correct, proper and timely data for their great decision. Therefore, designing a system and intelligent method of making decisions based on data (BI), particularly due to the management aspect of these ministries are very important. This method has caused the removal of a lot of works based on the assumption in organizations, and improves connections between departments and coordinating the activities for organizations to respond rapidly and properly to Changes in different conditions.

Due to the importance of this topic, this research aims to design an intelligent planning model at the Ministry of Science, Research and Technology based on business intelligence. The main question we are trying to answer in this research is: What is the appropriate and effective planning model in the Ministry of Science, Research and Technology? In fact, the main point that proves the need for this research is the lack of intelligent or non-systematic planning process, lack of timely and appropriate decision-making, lack of planning processes base on The evidence, organization moving away from the tasks of governance and paying or drowning in current work and the existence of too much data that makes it difficult for managers without a proper planning model. As result, it is necessary that designing a proper pattern makes it possible for managers of these ministries, which are the one the most important and effective organizations of making decisions and managing a country to make a precise, on time and decision. In this research, it has been attempted to design a proper planning pattern in the Ministry of Science, Research and Technology based on massive data. Given that no model has been designed and presented in the mentioned ministry so far, this is a testament that this research is an innovation.

The main objectives of the research can be classified as follows:

- Main purpose: Designing a proper model of the planning process in the Ministry of Science, Research and Technology in a detailed.

- Secondary purpose: Designing a suitable planning model in the Ministry of Science, Research and Technology in macro and detailed ways.

- Due to the stated goals, it is expected that this research will be able to define and determine different aspects of the research topic, and design a proper planning model in the Ministry of Science, Research and Technology in detail and present suggestions for future research and its implementation. 
- In fact, the purpose of this study is to design a smart and business intelligence based model by focusing on the correct process of data and information flow and processing it at different levels of decision making in both a macro and a detailed way. Therefore, this research seeks to find the appropriate answer to this question: "What is the appropriate model for planning (defining programs and actions) in the Ministry of Science, Research and Technology?"

\section{Material and methods}

\subsection{Literature review}

In this section of the research, we are attempting to review theoretical basics and the background based on the four main discussions utilized in review which are modeling, organization intelligence, business intelligence, structured analysis concerning the research topic which is a trilateral subject. Modeling means to make an abstract of a system that is focused on significant aspects, ignores irrelevant details, and analyzes the system [3]. Modeling is used in order to understand available factors and variables used in the problem, better and much simpler. Modeling comes up when one or many factors act together, affect a variable and affect each other mutually. Overall we can say that models are one of the main tools in today's science [4].

Modeling is one of the main activities in computer science it is often considered as an artificial go-between product for system development [5]. Conceptual modeling is a complex job that involves understanding the content of a subject and producing a symbolic artificial product to show various objects in that field or subject [6]. From an organizational point of view, intelligence is considered as a capability for a system to transfer data between inside and outside the environment, maintain stability, compatibility, and system development [7]. Exchanging and sharing of information in an organization is available through various methods including emotional, competitive, and environmental intelligence [8]. Intelligence is the ability to learn and utilize the organization's capability to create and use mental ability and to make and elevate knowledge. The intelligent organization is a set of patterns, ideas, and relative thoughts with an organization's aspects that is in great importance in the framework of the new environmental economy which arises from the information community [9]. The intelligent organization will coordinate the organization's abilities and working processes to make synergy [7]. Learning, making knowledge, fast response, and flexibility based on information technology is the basis of an intelligent organization [8][10]. The organization's intelligence requires that various aspects of an organization like decision-making, to be intelligent [11]. Being intelligent is having good decision-making and effective implementation of strategic decisions [12]. Based on a viewpoint and an approach, one of the ways of making intelligent organizations is to make them act intelligently in their essence [13].

We present an intelligent organization as part of an intelligent government because with the formation of intelligent organizations, in the end, an intelligent government will be formed. The intelligent government refers to a government that utilizes information technology's integration to make values for planning, managing, and operating for public production [14][15]. However, Wilensky in 1967 defined the organization's intelligence as gathering, processing, interpreting, and connecting required technical and political information for decision-making which this intelligence focuses more on inside of the organization's processes. If an organization wants to have a strategic position compared to its competitors, it has to use intelligent organizational processes and benefits more from its features compared to its competitors [16]. The intelligence of organizational processes includes vast fields of applications in surveillance and analysis of processes to optimize, forecast, homogeneity check and discover the organization's processes [17].

Many of the organizations that implemented planning and major organizational decision-making systems are still suffering from the deficiency of intelligence in their decision-making processes. As mentioned before, with the help of intelligent organizational processes we can make an intelligent organization. One of the ways of making intelligent organizational processes is using business intelligence. The main relation between business intelligence and organizational systems lies in the point that these system's secondary objective is to support decision-making for management and business intelligence can be placed at the heart of these systems and satisfy this goal. Because of this, we can acknowledge that making intelligence and utilizing business intelligence for designing and implementing policymaking patterns to optimize the organization's decision-making processes is inevitable for the organization. For an organization, being able to respond quickly in the events of market changes, they require intelligent managing systems for providing cause and reason analysis which to make this happen, we can use business intelligence. We can impute intelligence as the process of converting raw data to a business, practical, and management data that helps decisionmakers to make better and quicker decisions based on correct information [2]. We can use business intelligence for smartening decision-making processes in an organization like planning. Data will be processed by entering the business intelligence system and converted to knowledge to help managers using them in their decision-making. 
By using business intelligence, organization compares information and environmental indicators and predicts their working processes in the future. From Microsoft's point of view, business intelligence gives the ability to discover and analyze simpler information to decision-makers in all organizational levels to access, understand, analyze, cooperate and act easier on the information in every time and place [18]. The business intelligence system has the potential to maximize the use of information by improving the organization's capacity. This is the thing that Davenport names it as "Competition in analysis" [19]. Business intelligence is introduced not as a tool or product or even a system, but as a new approach in the organization's architecture. Business intelligence is not a new system or a software or an independent project but is a working framework including various processes, tools, and technologies that are required for converting data to information and information to knowledge. Also, with its help, we can determine the internal process efficiency of an organization. Also, Larson and Chang (2016) reviewed agile methods in data science and in the end, they proceeded to study the development of business intelligence lifetime. Big data phenomenon, size, variation, and data speed are 4 main factors that affect business intelligence and the use of information resulted from data [20].

Fink and his colleagues (2017) studied the relationship between business intelligence and organizational learning, in a paper. They studied the value creation process in an experimental way [21]. Banerjee and Mishra (2017) studied the strategies for managing the retailer's supply chain in India based on a business intelligence viewpoint. Based on their research, business intelligence has a meaningful relationship with customer relationship management and supply chain [22]. In a study, Arefin and his colleagues also reviewed the effects of strategy, structure, processes, and organization culture on the organization's effectiveness and intermediate role of business intelligence systems in them. In their point of view, the effectiveness of business intelligence systems is somewhat an intermediate between strategy effects, structure, processes, and organization culture [23]. The structured system analysis development method which has been used in this research is a completely different approach since 1980. This is not a new method. The structured term comes from structured programming. The structured word usually forces a structure with a disciplinary approach. This approach includes:

- System analysis

- $\quad$ Structured analysis

- $\quad$ Structured design

- Hardware study

Implementation and repair and maintenance[24]. In this method, the system is divided into small pieces and different levels from this division. After that, the data flow diagram will be made for visualization. The structured system design and analysis method have a special emphasis on structured system analysis and its documentation. So, by reusing developed systems and obtained experience, we can recover high-cost risk [25]. Logical data modeling based on developing system data requirements is done and documented. These data are determined based on entities and relations between these entities. Modeling data streams is related to data movements in information systems. The structured system analysis development method is a cascade approach that because of it, a sequence of events occurs in series and every step is continued from the last step (ITC Info tech India Ltd) [26]. Structured system analysis development method (SSADM), is a successful and useful method because it doesn't rely on a single method. This method is relying on three particular methods:

Modeling logic data that refers to identifying, modeling and documenting system data requirements.

Modeling data stream that expresses information flow around a system, the manner of modification and storing data and outside of the system data sources.

Modeling organizational behavior, identifying process, modeling and documenting business events that affect each institution and the series that occurs in it.

The most important reason for using the SSDAM method is that the outcome of carefully observing the system and its processes that it is offered using this method. So, ignoring part of the described system is not possible and a complete list of requirements is created [27]. Considering the described subject matter in structured analysis, for now, this method is used in various scientific and practical researches around the world. In the following, we refer to some of the most recent of these studies:

In a paper with the subject of an integrated web-based volunteer register system, Eneji and Eyong (2019) analyzed this system using the structured system analysis development method, cascade modeling, and object methodology [28]. 
Edebatu and Ekwonwune (2019) also researched the learning managing system for providing better service in an institution and used the structured system analysis development method. In this study, the process of defining a problem has been considered with a structured method and structured modeling, data flow chart, and a high-level model chart is provided [29]. Also, Jaja and Ibimina (2018) researched executing minor reference integrity in a system based on the database, using a qualitative method with structured analysis. The main goal of using this technic in design is to produce models of the system that can be analyzed in system development not only by the users but by the other parties involved in development [30]. Ekwonwune and his colleagues (2018), studied on conceptual modeling framework for establishing massive private infrastructures in the third-party information technology center, using the structured system analysis development method. The reason for using it was that this method made a systematic iterative of breaking and splitting a complex system into simpler parts [31]. Nahi and his colleagues (2017) used the structured system analysis development method which is the most standard and practical method in the majority of England government programs [32]. Dias (2017) analyzed a practical experience with one of the utilized tools in software engineering using a structured system analysis development method [33]. Barida (2019) used the particular suggested method in a paper titled, "advance applications of $\mathrm{C}$ algorithm in image classification process for identifying tumor contour and its geometric dimension". Due to this, the structured system analysis development method is used [34].

\subsection{Research methodology}

The research method is divided into two fundamental and applied categories. Fundamental research has sought to discover the facts and reality and understanding phenomena and objects that develop the boundaries of human general knowledge and discover scientific laws, they explain the characteristics and attributes of a reality [35]. In this research, as mentioned earlier, we are looking for an appropriate model for the planning process at the Ministry of Science, Research and Technology. So, this type of research will be fundamental. Also considering the use of the results of a fundamental part of the research with an intelligent approach to business intelligence-based decision making, research is also applied. As a result of the present study by type, it will be part of fundamental and applied research. In terms of method and method of exploratory research with qualitative research method and it is a scaling group. Qualitative research means any research that yields findings obtained in ways other than quantitative methods. Qualitative research of multifaceted interpretations, it recognizes the human experience and the recurring relationship within social and cultural systems.

Research has also been carried out in two phases (Phase I, macro pattern design and Phase II: detailed pattern design). In the first phase of the qualitative method and in particular, to construct the theory or design of the macro model in question, the "data-driven theory" or "grounded theory" was used. The data-driven theory is a qualitative research method by which, one theory or model is developed using a data set. Data theory is more likely to represent reality and since it is deduced from the data, it can, by creating a deeper understanding, a sure guide to action (Knowledge of the individual and Islam, 2011). Because we need a theory to explain the proper modeling of the planning process at the Ministry of Science, Research and Technology we use the grounded theory. When existing theories do not explain such a process, grounded theory can formulate a theory about the occurrence of this observed process. Therefore, these conditions justify the necessity of using this research method (qualitative-grounded theory). In the navigation section, interviews, questionnaires and documents were used. The following two methods were also used to collect the data:

Libraries: This method was used to gather information, study and analyze in depth the documentation to design the template.

Field: Because the present research is a qualitative and survey type exploratory research, exploratory and semistructured interviews (open questionnaire) were used. Using in-depth and face to face interviews with structured and semi-structured questioning, in-depth data were obtained from interviewers. The interview took about 20 hours $(1170$ minutes) to summarize the information needed.

Sampling in qualitative research in quantitative research is not random or non-random. Rather, it is a judgmental sampling method that is referred to as theoretical or purposive sampling. The sampling method used in this study consists of theoretical sampling based on expert opinion and the sample selection process the sample is also a snowball sampling method in which one participant or sample directs us to another. Targeted sampling cannot be planned prior to starting the study and formulating a data-driven theory. As a result, the sample size at the beginning of the work was unclear. But as the work progresses, from sampling to saturation or theoretical adequacy, thirteen of the statistical population were selected as sample size. Theoretical saturation is a phase in which no new data on concepts and categories of the phenomenon can be obtained. To analyze and describe information in the first phase of the research, initial coding of data was done row by line, phrase by phrase and paragraph by paragraph and the basic concepts and 
categories were determined. In secondary coding, by comparing concepts, similarities and commonalities were grouped into a single category. These categories were then linked together finally, the data were analyzed using coding and its requirements at the end, the appropriate policy model in the Ministry of Science, Research and Technology will be determined. Specifically, the fifth method or process of creating the Grounded Theory (method E) was used as follows:

Interviews, Field Notes, Observations, Documents, Books, Articles, Magazines, etc.

- Generation of basic data and information

- Data and information analysis

- Forming concepts and categories

Level 1: Basic Codes

Level 2: Classification and relationship determination

Level 3: Identify the underlying processes

- Development of concepts

- Subtractive sampling (saturation rule)

- A selective review of sources and texts

- Selective sampling of information

- The main variables

\subsection{Introducing Grundy Theory}

In the second phase of the research, the macro model presented in the first phase using the principles of Structured Analysis Method (SSADM), the analysis was performed and components of the pre-phase macro model were designed in detail and in detail. The Structured Analysis Approach is the Usage and Guide of the Basis Methodologies in Decision Making this leads to increased visibility, flexibility, and location in the slots. In this phase by laying the pattern designed in phase zero research, from the principles of the Structured Analysis Practical Method (which is a set of standards and guidelines for analysis and design), detailed planning design has been used in the Ministry of Science, Research and Technology based on business intelligence.

In this phase, the steps of constructing a detailed pattern were defined in terms of clearly defined tasks and tasks that have a definite relationship with each other. For this purpose, Entities, Relationships, Data Flow (DFD), Entity Linking and Relationship Linking (ERD), the attributes and storage of information and data were identified and their components identified and defined to accurately explain and document the activities and actions documented. Some methods of analyzing functions using data flow diagrams (DFDs) or entity relations diagrams (ERDs) and others emphasize data analysis using the data model. But the structured analysis approach uses both approaches he uses various techniques during his various stages (Weaver, 2006). The end product of this phase is the development and design of a rational and detailed model of entities, relationships and data. Entities actually represent the same process or operation performed on the data. Relationships are also the interface or part that links data to entities.

In this phase, the preliminary explanation and classification of the information and evidence resulting from the systematic analysis are based on the principles of the SSADM method. The results of this preliminary explanation and closure based on the model components designed in the first phase of the research and outputs are presented in the Findings section. In qualitative research, the validity and reliability of quantitative methods are similar there is no definite principle of fortune. Researchers focus on the qualitative and quantitative studies of quantitative research, instead of validity and reliability, they have invented new concepts such as validating results (transferability) and evaluating research quality (verification). The criterion for evaluating the quality and validity of a qualitative study by the grounded theory method, it relies on evaluating its proposed theory as well as on the ways that it has led to its development. Therefore, the following four techniques were used simultaneously to assess the validity and quality of research results: 
Trilogy: Troubleshooting resources, expert opinions, and multiple methods were used during data collection and analysis to increase validity.

Obtaining accurate parabolic information: For analysis and coding, information from other research and other sources of information was obtained to help increase the validity of the research.

Researcher self-review: During the data gathering and analysis process, a peer researcher was used to review the data collection and analysis.

Member Controls: Data and output analyzes were presented to 35\% of the statistical population and their responses were used to refine and summarize the results.

\section{Results and discussion}

\subsection{Experimental analysis}

Using the data-oriented method (E), research data has been collected and analyzed with the zig-zag method. from the moment entering the field of study, at the time of collecting data, analyze, coding and validation till the time of creating a theory or considered algorithm, data always compared, analyzed and coded in different aspects by contemplation. That means the data and information at first produced with the help of interviews, in-depth library study, review of documents, etc. Then the data were analyzed in parallel and simultaneously.

The formation of the concepts at the first level was based on the main codes, at the second level on classification and the third level based on the detection of the principal and subdivision relation between parts and other effective Phenomenon. Then the development of concepts continued based on theoretical sampling, selective review of texts and resources. Finally, by defining the concepts, categories, summarizing the relations, components and effective phenomenon, the grounded theory or planning model was presented.

In the first step of this phase, a total of 193 initial codes were set up to create an organized set of codes and basic concepts that is the result of the detailed examination of each interview's statements and a thorough study of the documentation in parallel. In the second step, the initial codes were categorized so that the capability of usage and Implementation of them get easier. The criterion for classifying concepts and basic codes is their conceptual fit with the executive mechanism to classify them into concepts and categories. In this step, the concepts (main classes) and categories (subcategories) are classified below.

In the third step, subjects that had similar use and nature were grouped together to form key components due to semantic and functional fit. In step four, the relations between the key components were classified to determine the type of their relations. Then user levels were identified and categorized by type and the source of decisions. performed analysis in this phase (step one to five) was assigned to the encoding tables to create a theory from the gained data (pattern design),that because of the size of the tables and the limitations on the number of pages in the article, the attachment (including tables one through five) has been prepared for researchers' use. Based on the coding and categorization of the data in the above steps (the relevant table) and the Grounded Theory (E) method, the obtained theory from data means the macro planning model at the Ministry of Science, Research and Technology based on Business Intelligence designed in VISIO.16 figure 1 represents a huge pattern designed. 


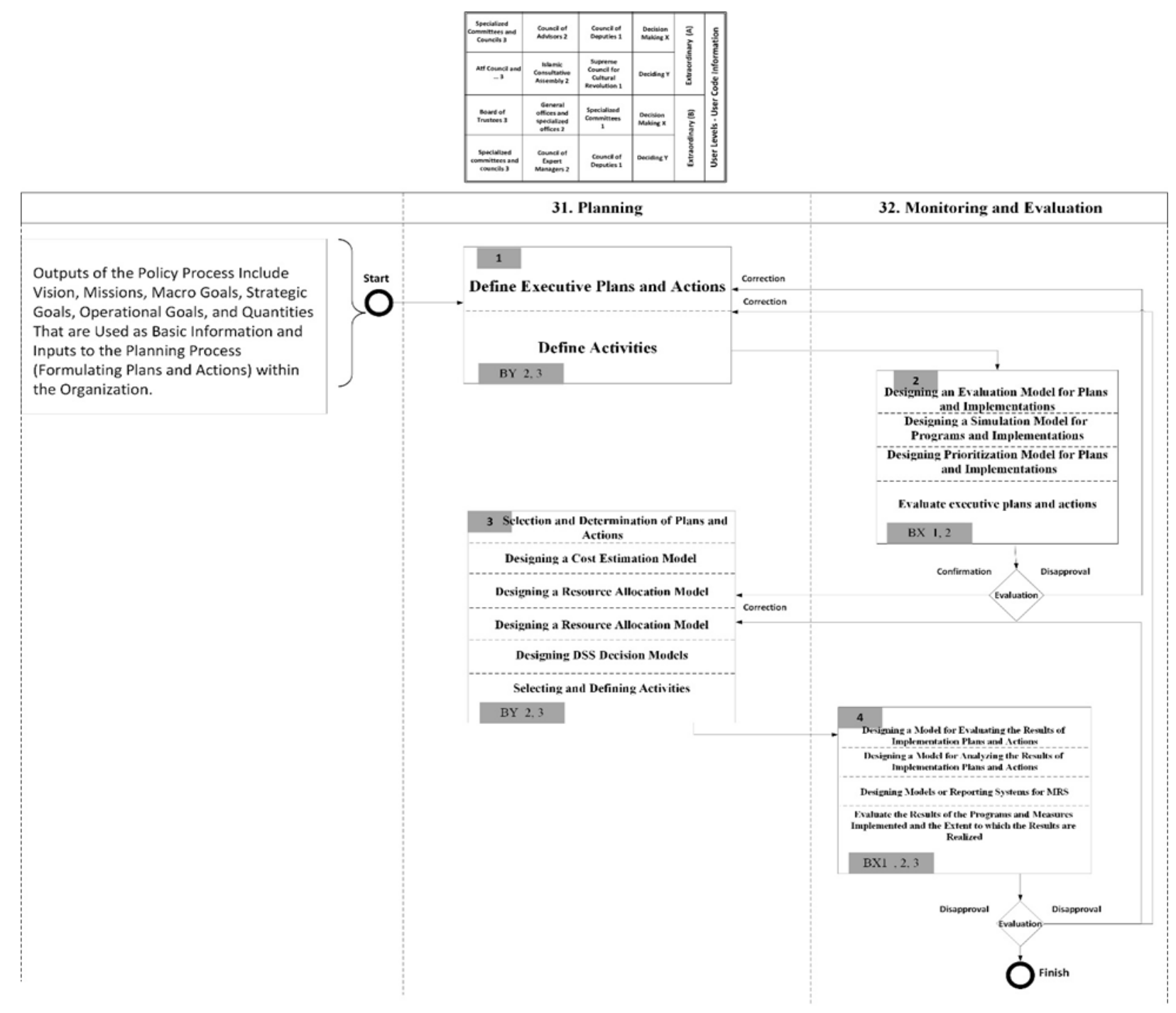

Figure 1 Macro model of business intelligence-based planning in the ministry of science, research and technology from grounded theory.

In the second phase of the research, the macro model presented in the first phase was analyzed using the principles of Structured Analysis Method (SSADM) and components (four components / codes) specified in the previous phase of research detailed design and outputs were provided in detail. In fact, in this phase it was attempted to base the pattern designed in the first phase of the research, from the principles of the applied method of structured analysis (Which is an interconnected set of standards and guidelines for analysis and design), To be used for detailed design of the planning template in the Ministry of Science, Research and Technology based on business intelligence. In this phase, the process of constructing a detailed template in the form of clearly defined activity and tasks and they have a definite relationship with each other, it has come to pass. For this purpose Entities, Relationships, Data Flow (DFD), Entity Linking and Relationship Linking (ERD), the features and location of the data and data storage were determined and its components identified and defined to clearly explain and document how activities and activities are documented and documented what documentation will be produced at each stage of system development this is highlighted in the component model (four codes / components) designed to store data. The end product of this phase is the development of a rational and detailed model of entities, Relationships and data, including a graphical representation of the logical construction of data, the inventory is the description of the information items, the scope of the information items. Entities actually represent the same process or operation performed on the data. Relationships are also the interface or part that links data to entities. Attributes also represent and explain the essential features of entities or relationships. In order to design the detailed model in question, first explain and initialize the information and the evidence from the systematic analysis was based on the principles of the SSADM method. The results of this analysis and the analytical classification based on the four components of the model designed in the first phase of the research, The relevant tables were purified and analyzed these tables have also been attached (including tables six and seven) due to their size and limitations on the number of pages of paper to be used by researchers. After completing the analyzes of this step using the structured 
analysis method, The detailed planning model at the Ministry of Science, Research and Technology was designed and plotted using the information in the relevant tables (presented in the appendix). This detailed model uses Structured Analysis Principles (SSADM) separately for quadruple macro model components resulting from the first phase of research, that is, the macro planning model was designed in VISIO.16 by the Ministry of Science, Research and Technology-based Business Intelligence. Figures 2 to 5 illustrate the detailed pattern designed for these four components.

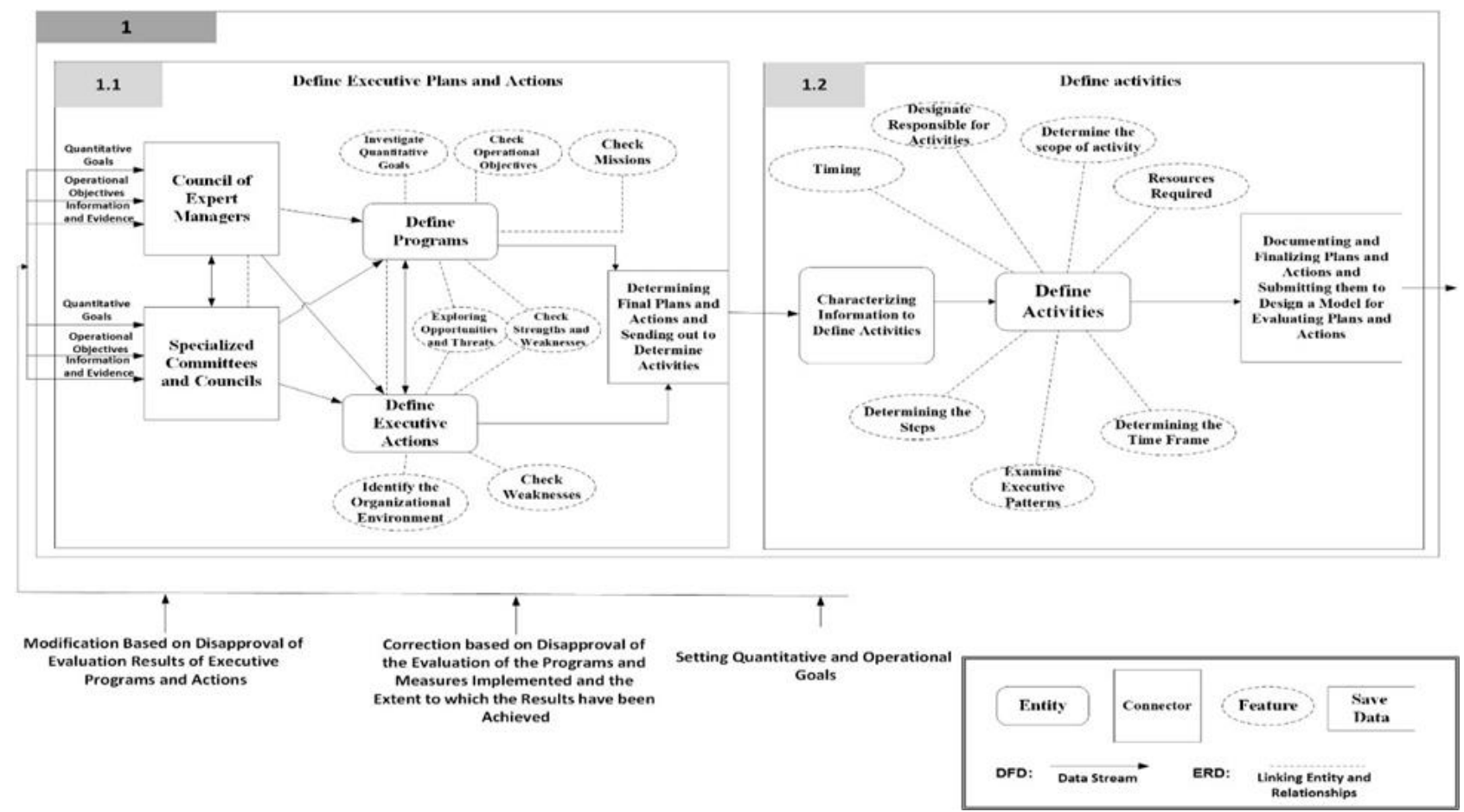

Figure 2 First detailed scheduling pattern (Designed based on SSADM)

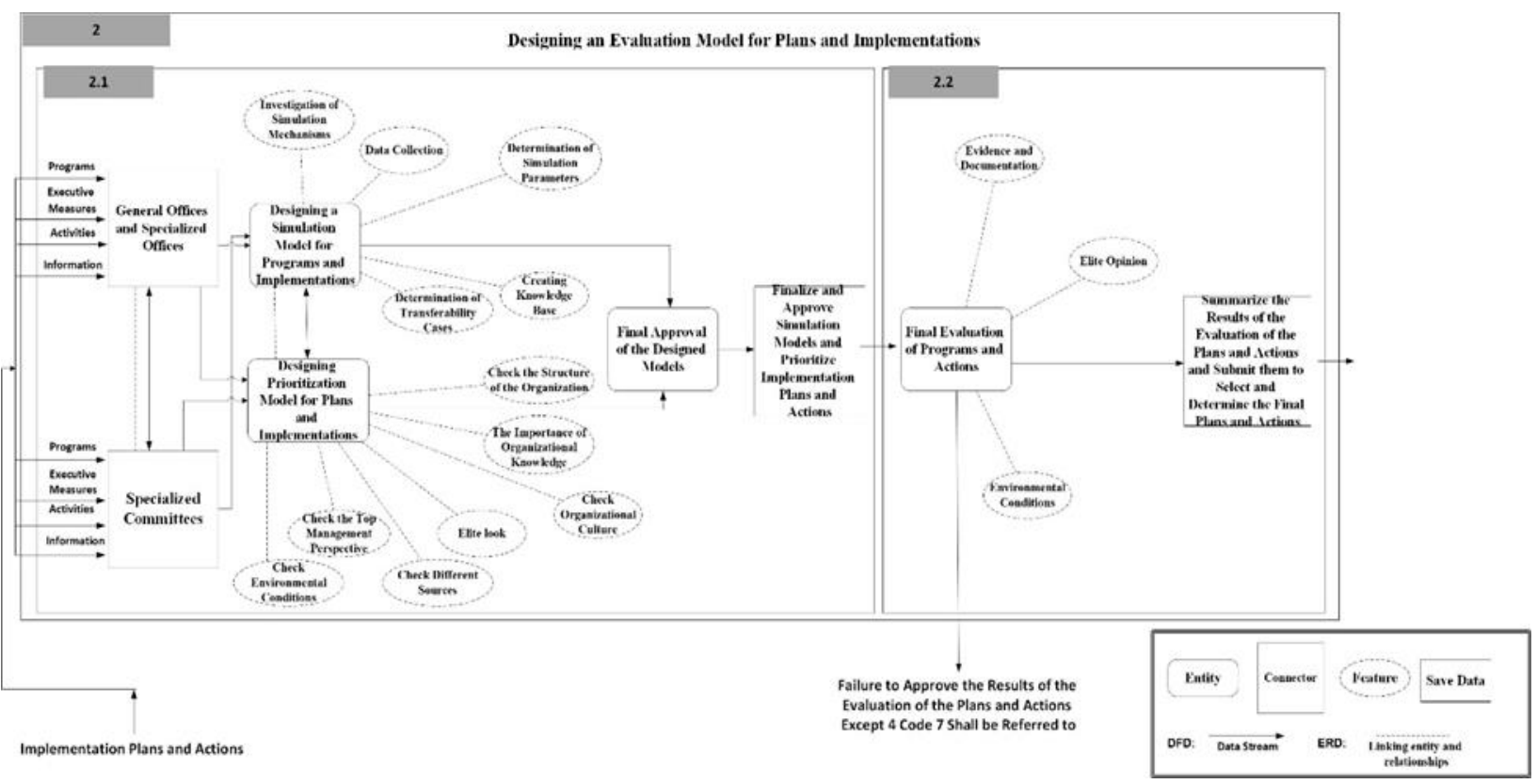

Figure 3 Second detailed scheduling pattern (Designed based on SSADM) 


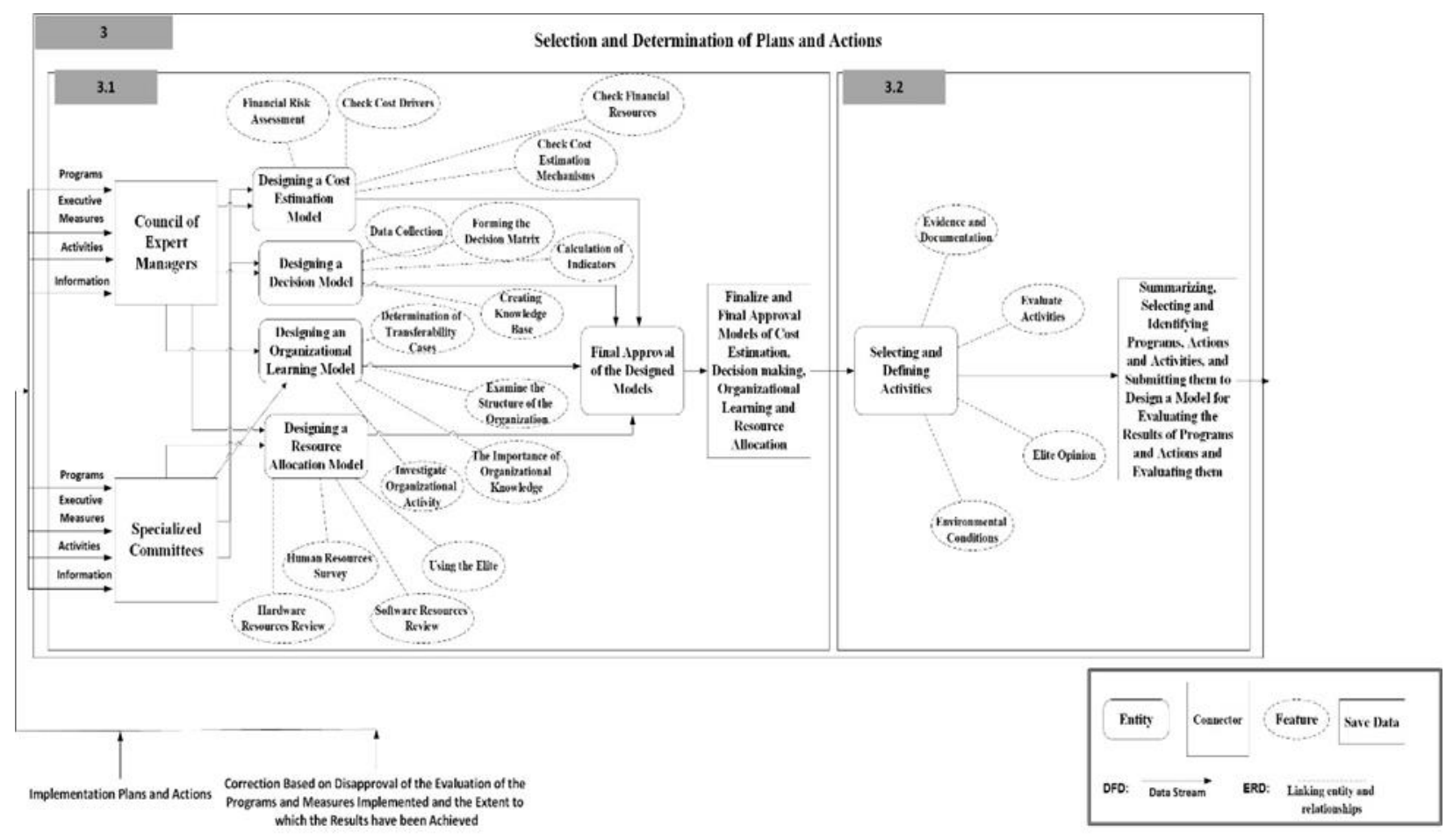

Figure 4 Third detailed scheduling pattern (Designed based on SSADM)

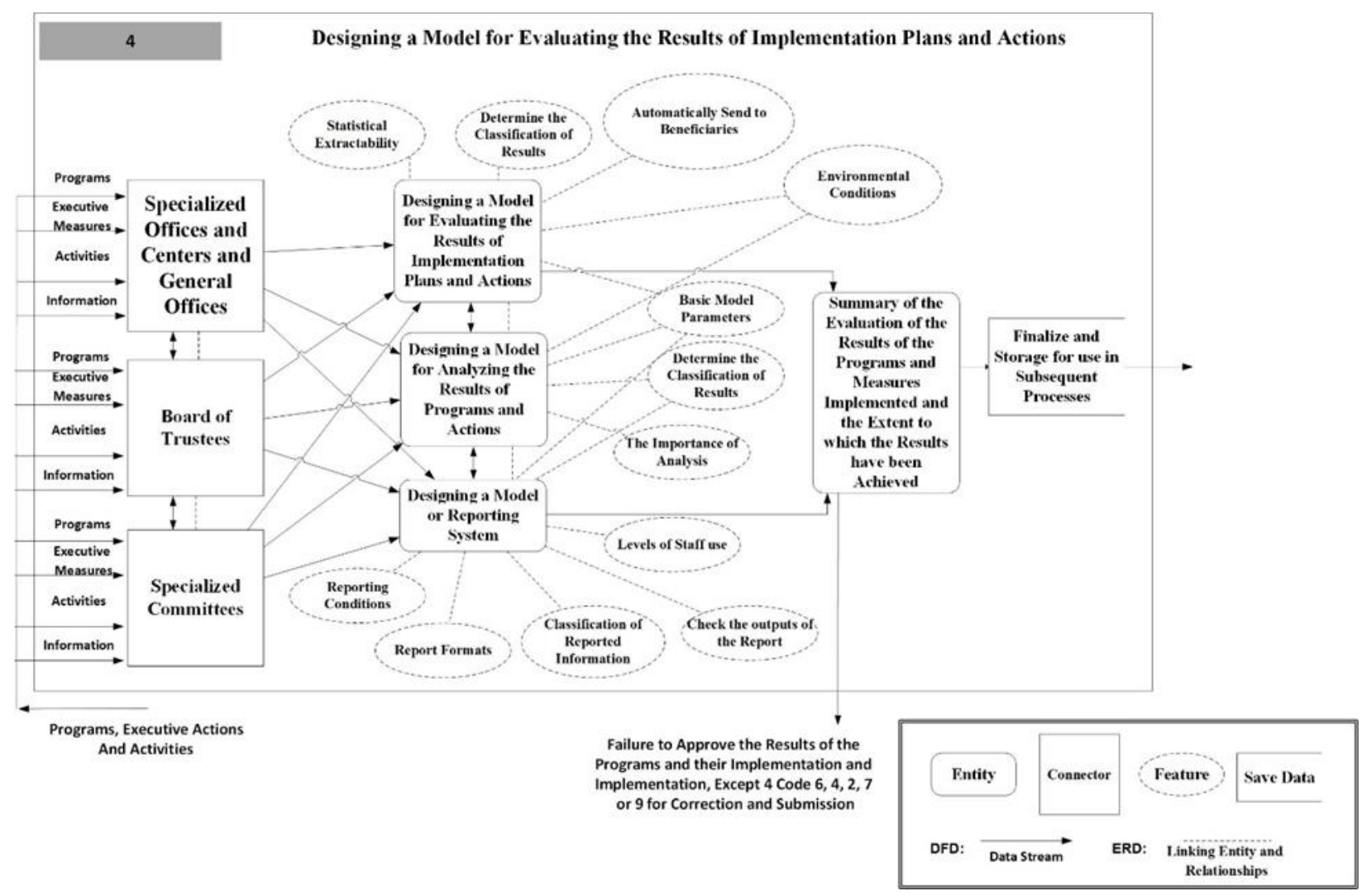

Figure 5 Fourth detailed scheduling pattern (Designed based on SSADM) 


\subsection{Analytical results}

To evaluate the presented model quantitatively, a questionnaire has been designed to evaluate the quality and reputation of the model based on experts' opinions. To determine the narrative of the questionnaire, firstly the questionnaire has been distributed between $25 \%$ of the statistical society (policy-making managers of the studied organization) to debug any problem, and finally, after this stage, the narrative of the questionnaire has been approved by consulting professionals. To find the reliability coefficient the Cronbach alpha has been used in SPSS software. The resulted alpha value $(76 \%)$ is a suitable value which implies the trust and reliability factors of the questionnaire. As introduced the statistical society are the policy-making managers of the ministry of science, research, and technology which includes operation executive and staff managers along with consultants. After setting the statistical society, the statistical sample, the number of respondents, and their choices should also be determined. To achieve this, Parker and Henry's method (1990) has been used for determining the minimum sample. This method is available by a table that has been published by authors. In this method, if the number of statistical society is less than 200:

$\mathrm{N}<200$

And the reliability coefficient is $95 \%$, meaning:

$\mathrm{e}=95 \%$

And considering the margin error of $3 \%$, meaning:

$\mathrm{r}=3 \%$

In this case, the minimum number of sampling equals to the whole statistical society, meaning:

$\mathrm{N}^{*}=\mathrm{N}=57$

This means that in the introduction model by Parker and Henry if the number of the whole society for sampling navigation direction is less than 200 , the whole society should be sampled and directed (Edwards and colleagues, 1384). The questionnaire of the research consists of two parts. The first part which the related evaluation of it is presented here includes gender, education rate, and years of service. Based on the extracted information and the processed evaluation, from 34 respondents of the questionnaire, 25 were men and 9 were women which give $73.5 \%$ to men and 26.5 to women. Of these, 11 people had bachelor, 15 people had MA, and 8 people had a Ph.D. which gives $32.4 \%$ of bachelors, $44.1 \%$ of MA, and $23.5 \%$ of Ph.D. The diploma and associate degrees were not included in the respondents.

Between respondents of the questionnaire, 12 people had less than 5 years of service (35.3\%). 9 people had over 5 to 10 years of service (26.5\%). Over 8 people had 10 to 15 years of service $(23.5 \%)$ and 5 people had over 20 years of service (14.7\%). There was no one with more than 20 years of service in statistical society. According to Table 1, the questionnaire of research has 5 main questions that have used the Double rating scale technique (agree, disagree). The verified results of the introduced model have been verified by experts and are mentioned below:

Table 1 The questionnaires of the proposed analytical results

\begin{tabular}{|l|l|c|c|c|}
\hline SN. & Question title & Disagree & Agree & Agreed percentage \\
\hline 1 & Ontology (choosing proper problem) & 3 & 31 & $91 \%$ \\
\hline 2 & Methodology (reliability and data and research procedures) & 1 & 33 & $97 \%$ \\
\hline 3 & Cognition (multiple perceptions and worthiness) & 7 & 27 & $79 \%$ \\
\hline 4 & $\begin{array}{l}\text { Generalizability (suitability of the subject for rejection or } \\
\text { approval of the theory) }\end{array}$ & 5 & 29 & $85 \%$ \\
\hline 5 & $\begin{array}{l}\text { Structural validity (reproducibility, cause of subjects and base } \\
\text { description) }\end{array}$ & 2 & 32 & $94 \%$ \\
\hline Total evaluation results & 18 & 152 & $89 \%$ \\
\hline
\end{tabular}

Table 2 Method and results of validation and quality.

\begin{tabular}{|l|l|l|l|l|l|l|}
\hline $\begin{array}{l}\text { Predicted } \\
\text { components in } \begin{array}{r}\text { Key } \\
\text { pattern }\end{array}\end{array}$ & $\begin{array}{l}\text { Research } \\
\text { er coding }\end{array}$ & \multicolumn{2}{|l|}{ Secondary encoder view } & Expert opinion & Final \\
\cline { 3 - 5 } & & Acceptance & Revision & Acceptance & Revision & \\
\hline
\end{tabular}




\begin{tabular}{|c|c|c|c|c|c|c|c|c|}
\hline \multicolumn{2}{|c|}{$\begin{array}{l}\text { First Detailed Scheduling } \\
\text { Pattern }\end{array}$} & * & \multicolumn{2}{|c|}{ * } & & & * & * \\
\hline \multicolumn{2}{|c|}{$\begin{array}{l}\text { Second Detailed Scheduling } \\
\text { Pattern }\end{array}$} & * & & & * & & * & * \\
\hline \multicolumn{2}{|c|}{$\begin{array}{l}\text { Third Detailed Scheduling } \\
\text { Pattern }\end{array}$} & * & \multicolumn{2}{|c|}{ * } & & * & & * \\
\hline \multicolumn{2}{|c|}{$\begin{array}{l}\text { Fourth Detailed Scheduling } \\
\text { Pattern }\end{array}$} & * & & & * & * & & * \\
\hline \multicolumn{9}{|c|}{ Macro pattern derived from Grounded theory } \\
\hline \multicolumn{3}{|c|}{ Researcher evaluation and validation } & \multicolumn{2}{|c|}{ Expert opinion } & \multicolumn{4}{|c|}{ Member controls } \\
\hline $\begin{array}{l}\text { Triangle } \\
\text { Making }\end{array}$ & $\begin{array}{l}\text { Parallel } \\
\text { information }\end{array}$ & $\begin{array}{l}\text { Self- } \\
\text { review }\end{array}$ & $\begin{array}{l}\text { Acceptan } \\
\text { ce }\end{array}$ & Revisio & $\begin{array}{l}\text { First } \\
\text { member }\end{array}$ & $\begin{array}{l}\text { Second } \\
\text { member }\end{array}$ & $\begin{array}{l}\text { Third } \\
\text { member }\end{array}$ & $\begin{array}{l}\text { Fourth } \\
\text { member }\end{array}$ \\
\hline * & * & * & * & & Accepted & Accepted & Revised & Accepted \\
\hline
\end{tabular}

\section{Conclusion}

In order to validate and evaluate the quality of research outcomes, we used triangulation, detailed paralleled information gain, researcher and members control's self-evaluation (sometimes used paralleled and in the operation and at the end of it). To get better results we used a fellow researcher (secondary coder) in the research. In order implement members control technic, 5 people (35 percent) of the statistical population had been chosen to validation and evaluate the research quality. Comments and corrections of fellow researcher and members have been done after final improvement from experts. The table 2 illustrates the validation and evaluation of research outcomes quality.

The innovation of paper and predefined goals, lack of a certain pattern, lack of attention to previous researches, absence of a suitable tool for planning, evaluation based on data and evidence (Intelligent) and scattering of recommendations and necessary actions for mentioned process, proves the importance of research outcomes.

We also answered and evaluated the main question and secondary questions of the research which were presented due to the main question and designed with the format of planned pattern based on business intelligence (circulation and proper processing of data).The main outcomes of this research, designing semantic pattern in ministry of science research and technology (regarding the whole educational, research and technologic missions) is massive and detailed which has provided a comprehensive and intelligent attitude based on business intelligence in the aspect of circulation, proper processing along with evidence in this field. Finding experts is one of the main challenges and limitations of the research, due to the lack of experts with tetrahedron experience (policy-making and planning, intelligence and information technology, higher education, and system analysis). To overcome this limitation, considering using managing expert's opinions and by using the snowball-sampling method, we also got help from information technology managing experts. Further, facing problems in accessing some of the required information despite of researcher's broad connection with executive organizations.

We can classify whatever we used for improving and developing the process of intelligent planning in the format of a national approach. With the development of intelligent governments around the world and substation of smartening approach instead of traditional approach, it is suggested that intelligent patterns be designed in other fields of decisionmaking like policy-making. Also, it is suggested that, similar patterns in other organizations and ministries be designed based on that organizations or ministry's conditions and coordinates. Further, by linking between designed patterns in various governmental organizations and relating it with major planning pattern in government level (planning and budget organization), the pattern of intelligent government planning in Iran be designed and implemented. Of course, one of the main challenges of this subject is the lack of technologic and modern understanding of issues in senior officials. We suggest that in order to execute and implement the designed research pattern using scientific and practical methods, the detailed pattern must be designed by using integrated programming languages (object oriented) in a way that can be run in an organization. Finally, some limitations of this research are as follows:

- Proving soundness and completeness of the proposed model should be evaluate using formal methods.

- Number of experts to evaluate the existing questionnaires can be increased based on their expertise. 
- $\quad$ The proposed model can be used any enterprise information systems such as healthcare and medical ministry, defense ministry and etc.

\section{Compliance with ethical standards}

\section{Acknowledgments}

The authors owe it to themselves to thank and appreciate all the contributors to this article. We would like to thank all the interviewees who contributed to the qualitative part of the article.

\section{Disclosure of conflict of interest}

The authors do not have any conflict of interest.

\section{References}

[1] Amid Amin, Moalagh Morteza, Zare Ravasan Ahad. Identification and classification of ERP critical failure factors in Iranian industries, Information Systems. 2012; 37: 227-237.

[2] Ong IL, Siew PH, Wong SF. A five-layered business intelligence architecture. Communications of the IBIMA. 2011 Jan 1.

[3] Bruegge B, Dutoit AH. Object Oriented Software Engineering Using UML: Patterns, and Java ${ }^{\mathrm{TM}}$, Technical University of Munich Department of Computer Science Munich, Germany and Carnegie Mellon University School of Computer Science Pittsburgh, PA, United States, Third Edition, 2010.

[4] Frigg R, Hartmann S. Models in Science. In: Zalta, E.N. the Stanford encyclopedia of philosophy. 2012.

[5] Thalheim B. The art of conceptual modelling, Frontiers in Artificial Intelligence and Applications. 2012; 237: 149168.

[6] Carvalho VA, Almeida JPA. Toward a well-founded theory for multilevel conceptual modeling. Software \& Systems Modeling. 2018; 17(1): 205-231.

[7] Sydanmaanlakka Pentti. Intelligent leadership and leadership competencies. Developing a leadership framework for intelligent organizations. HUT Industrial Management and Work and Organisational Psychology Dissertation Series No 4, 2003; 1459-1936.

[8] Staskeviciute I. Development of Intelligent Organization in the context of internal organizational Dimension Transformation, Summary of the Doctoral Dissertation, [Ph.D. dissertation]. THESIS DEFENSE, Management and Administration, Kaunas, Kaunas University of Technology. 2009.

[9] Erastos F, Eoin B. Towards the smart organization: An emerging organizational paradigm and the contribution of the European RTD programs, Journal of Intelligent Manufacturing 12. 2001; 101-119.

[10] Alavi M, Gallupe RB. Using information technology in learning: Case studies in business and management education programs. Academy of Management Learning \& Education. 2003; 2(2): 139-152.

[11] Schwaninger M. Managing Complexity ${ }^{2}$ the Path Toward Intelligent Organizations, Journal of Systemic Practice and Action Research. 2000; 13(2): 207-239.

[12] Filos E, Banahan E. Towards the smart organization: An emerging organizational paradigm, Journal of Intelligent Manufacturing. 2001; 12: 101-119.

[13] Wiig KM. The Intelligent Enterprise and Knowledge Management, Knowledge Research Institute, Inc., UNESCO's Encyclopedia of Life Support Systems. 2000.

[14] Howard R, Maio AD. Hype cycle for smart government, 2013-07-22)[2015-03-10].

[15] Chen SC, Miau S, Wu CC. Toward a smart government: an experience of e-invoice development in taiwan. 2014.

[16] Kuosa T. Different Approaches of Pattern Management and Strategic Intelligence, Science Direct. 2011; $458-467$.

[17] Grigori D. Business Process Intelligence, Computers in Industry. 2003; 53(3): 321-343.

[18] Tutunea MF. Business Intelligence Solutions for Mobile Devices- An Overview. Procedia Economics and Finance. 2015; $27: 160-169$. 
[19] Davenport TH. Competing on Analytics. Harvard Business Review. 2005; 84(1): 98-107.

[20] Larson D, Chang V. A review and future direction of agile, business intelligence, analytics and data science, International Journal of Information Management. 2016; 36(5): 700-710.

[21] Fink L, Yogev N, Even A. Business intelligence and organizational learning: An empirical investigation of value creation processes, Information \& Management. 2017; 54(1): 38-56.

[22] Banerjee M, Mishra M. Retail supply chain management practices in India: A business intelligence perspective, Journal of Retailing and Consumer Services. 2017; 34: 248-259.

[23] Arefin M, Hoque M, Bao Y. The impact of business intelligence on organization's effectiveness: an empirical study, Journal of Systems and Information Technology. 2015; 17(3): 263-285.

[24] Cosmas IN, Christiana FA, Jeremiah 00, lkechukwu CA. Transitions in System Analysis and Design Methodology, American Journal of Information Science and Technology. 2018; 2(2): 50-56.

[25] Essays UK. Structured systems analysis and design. Retrieved in 2018.

[26] ITC Infotech India Ltd. Structured Systems Analysis and Design Methodology. 2012; 2-7.

[27] Avison DE, Fitzgerald G. Information Systems Development: Methodologies, Techniques and Tools, McGraw-Hill, Maidenhead. 2002.

[28] Eneji S, Eyong W. Integrated Web-Based Voter Registration System (For Developing Countries), International Journal of Innovative Science and Research Technology. 2019; 4(2): 261-275.

[29] Edebatu DC, Ekwonwune EN. Learning Management System for Improved Service Delivery in Tertiary Institution, Int. J. Communications, Network and System Sciences. 2019; 12: 37-48.

[30] Jaja, Ibimina A. Enforcement of Partial Referential Integrity in a Database System, International Journal of Computer Science and Mathematical Theory. 2018; 4(2): 27-33.

[31] Ekwonwune EN, Anyiam CD, Osuagwu OE. Modelling Conceptual Framework for Private Cloud Infrastructure Deployment in the ICT Centre of Tertiary Institutions. Communications and Network. 2018; 10: 117-125.

[32] Nahi AA, Gulumbe MA, Selamat NS, Ismail NB, Dahlan HM, Hashim MM. A Review of Blended Methodologies Implementation in Information Systems Development, Journal of Inf ormation Systems Research and Innovation. 2017; 11(1): 7-15.

[33] DIAS G. Evolvement of Computer Aided Software Engineering (CASE) Tools: A User Experience, International Journal of Computer Science and Software Engineering (IJCSSE). 2017; 6(3).

[34] Barida B. An Enhanced Application of Fuzzy C-Mean Algorithm in Image Segmentation Process, Journal of Scientific and Engineering Research. 2019; 6(1): 193-197.

[35] Saravanavel P. Research Methodology, Published by Kitab Mahal, ISBN 10: 8122501060 / ISBN 13: $9788122501063,2013$.

\section{Author's short biography (optional)}

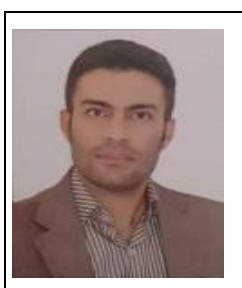

Dr. Ahad Banar

Born in 1986, PhD in Public Policy, Lecturer in Department of Public Management, Central Tehran Branch, Islamic Azad University, Tehran, Iran And a researcher in the fields of health system, management, design and systems analysis, Planning and policy making.

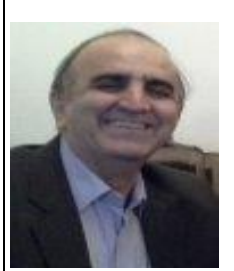

\section{Dr. Azizollah Memariani}

Born in 1960, PhD in Mathematics (O.R.), full Professor in Faculty of Computer and Electrical Engineering, Kharazmi University, Tehran, Iran And has research and teaching chairs in major Iranian universities And specialist in the Optimization, Multiple Criteria Decision Making, Fuzzy Systems, Decision Support Systems, Data Envelopment Analysis, Data Mining and Knowledge Engineering, Higher Education, Smart Governance. 


Dr. Ali Rezaeian
Born in 1944, PhD in Behavioral management (management improvement), full Professor in Faculty
of Management and Accounting, Shahid Beheshti University, Tehran, Iran And has research and
teaching chairs in major Iranian universities And specialist in the Organizational Behavior,
Management and Organization, Management System analysis and design, Administrative
management, planning, policy making and Theories of organization.

